\title{
Experiments and Modeling of Thermal Quenching in a Pilot Scale Delayed Coker
}

\author{
Keith D. Wisecarver \\ Russell School of Chemical Engineering \\ University of Tulsa, Tulsa, Oklahoma, USA \\ keith-wisecarver@utulsa.edu
}

\section{Extended Abstract}

Delayed coking is a petroleum refining process in which the high-boiling fraction of crude oil is thermally cracked by heating to $\sim 482-500^{\circ} \mathrm{C}$ [1]. The hot fluid is sent to a drum where petroleum coke is formed from the remaining liquid while the cracked vapor product is allowed to escape. Once the drum has filled with solid coke, flow is switched off, the coke bed is steam stripped to remove any remaining liquid, and the bed is then thermally quenched by the addition of water before the drum is opened and the coke cut out [2]. The quenching step is of special importance industrially from a safety standpoint, because an improperly quenched coke bed can present a serious hazard of steam eruptions when cutting out the coke [3].

The pilot scale delayed coking unit at The University of Tulsa consists of a vertical coke drum $0.076 \mathrm{~m}$ in diameter and $1.8 \mathrm{~m}$ in height. A series of tests was conducted using a variety of feedstocks to determine the effectiveness of the quench process. An internal thermowell was used to measure temperatures every $0.26 \mathrm{~m}$ along the centerline of the coke bed. As quench water is fed to the bottom of the drum it is initially vaporized to steam due to contact with the hot coke. Once the very bottom of the drum is quenched a moving front of liquid water proceeds up the porous coke bed. In a properly quenched coke bed, the temperature at each thermocouple shows a steep decline as the water front reaches the thermocouple. Improper quenching, due to dense sections of coke that the water cannot penetrate due to locally high density and/or tight pore structure, often shows up as deviations to this smooth temperature front. However, it was discovered that even coke beds that show a smooth temperature profile often contain hot spots in regions away from the thermocouples.

A heat transfer model was developed that includes conduction, convection, and radiative heat transfer from the coke bed. This model allows calculation of the quench efficiency, defined as the ratio of the mass of coke accessible to water to the total mass of coke. From this model, it was possible to draw conclusions on the effect of feedstock properties and operating conditions on the quench efficiency. One important conclusion is that quench efficiency shows a strong inverse correlation to the average overall density of the coke bed, which in turn is a function primarily of feedstock properties.

\section{References}

[1] J. H. Gary, G. E. Handwerk, and M. J. Kaiser, Petroleum Refining Technology and Economics, $5^{\text {th }}$ ed. CRC Press, 2007.

[2] K. Wisecarver, "Delayed Coking," in Springer Handbook of Petroleum Technology, C. Hsu and P. Robinson, Eds., 2017, pp. 903-913.

[3] P. J. Ellis and C. A. Paul, "Tutorial: Delayed Coking Fundamentals," paper T9005-a, AIChE 1998 Spring National Meeting, New Orleans, LA, March 8-12, 1998. 